Research Article

\title{
People, Means, and Activities: A Conceptual Framework for Realizing the Educational Potential of Makerspaces
}

\author{
Avneet Hira (iD) and Morgan M. Hynes \\ School of Engineering Education, Purdue University, West Lafayette, IN 47906, USA \\ Correspondence should be addressed to Avneet Hira; ahira@purdue.edu
}

Received 21 December 2017; Revised 19 March 2018; Accepted 18 April 2018; Published 3 June 2018

Academic Editor: Paul S. Szalay

Copyright (C) 2018 Avneet Hira and Morgan M. Hynes. This is an open access article distributed under the Creative Commons Attribution License, which permits unrestricted use, distribution, and reproduction in any medium, provided the original work is properly cited.

\begin{abstract}
Makerspaces are environments where individuals use technologies to make physical artifacts within a community of fellow Makers. There has been growing interest in the educational potential of Making activities which has resulted in many schools procuring tools and technologies to set up their Makerspaces. However, there is scant research investigating the efficacy of Making these newly emerging Makerspaces intended for learning. In our work, we narrow this gap in knowledge between the claimed educational potential of Making and its attainment. By synthesizing prior work and publically available data on Makerspaces, we introduce a framework to situate the educational considerations for Makerspaces and recommend directions for future research on educational Makerspaces. Being cognizant of the Maker culture having emerged outside of the academic literature, we synthesize publically available data from 53 untraditional but relevant sources. These sources include definitions of Making forwarded by 3 well-established Maker initiatives (Makerspace, Hackerspace, and Fab Lab), 18 relevant sites of Making activities across the United States, 17 sites from other countries (namely, China, India, Morocco, and Spain), and 15 Maker initiatives at schools in the United States. After proposing and detailing the framework, we recommend directions for future research to attain the potential of educational Making.
\end{abstract}

\section{Introduction}

Makerspaces are emerging as educational spaces in schools, libraries, and museums all over the world. Some proponents of educational Making believe that it sparks innovation and critical thinking skills in students by engaging them in hands-on learning experiences [1,2]. Educators have begun to adopt this belief and are developing new curricular activities and materials for Making as an educational endeavor [3-7]. However, there is scant research investigating the efficacy of Making in these newly emerging Makerspaces for learning. The limited nature of the research is the motivation behind our work. By synthesizing prior work and publically available data on Makerspaces, we introduce a framework to (1) situate the educational considerations for Makerspaces (2) and recommend directions for future research on educational Makerspaces.

In the following sections, we discuss the oft-cited potential benefits of Makerspaces for education as well as the potential challenges in realizing these potential benefits. The potential benefits are rooted in a number of theories of learning and development such as, constructionism, experiential learning, self-efficacy, and agency. The challenges relate to issues of cultural and ideological differences and the precarious quality of self-directed design learning.

1.1. The Promise of Makerspaces for Educational Settings. Dale Dougherty characterizes Making as inherently human [8]. Making can be traced throughout history as we continue to make tools and technologies aimed at creating more fulfilling lives. Mark Hatch who authored the Maker Manifesto [9] invokes a similar belief stating, "making is fundamental to what it means to be human" (p. 1). Characterizations such as that of Dougherty and Hatch have appeared in popular media about Making and the role of Making in the democratization of invention. For example, Dubrow [10] posits "[t]o its advocates and participants, the 
Maker Movement resonates with all of those characteristics that we believe makes America great: independence and ingenuity, creativity and resourcefulness." Many community Makerspaces seem to adopt similar ideas with statements such as "if you can think it up, you can bring it to life here" [11] making way to their agendas. Given public concern about a growing disconnect between people and the objects with which we interact (a concern often attributed to consumerism), Making has the potential to engage learners in ways that bring them closer to these objects reconnecting to the basic human aspects of engaging with the world.

Makerspaces have also become to be known as places where people can pursue their creativity by Making things that are personally meaningful to them no matter their utility to the broader public. This has manifested in the implementation of Makerspaces that are described with phrases such as "Making future dreams a reality" [12]. Barniskis [13] also wrote about how Making as a hobby manifests from the everyday needs and wants of individuals. Having a space to be able to Make what is personally meaningful to an individual is often the biggest selling point of newly constructed commercial Makerspaces [14], which has translated into the promise of educational activities that connect to students' interests and passions. This promise of Makerspaces can roughly translate to the idea that a learner who is choosing what they want to make is bound to be more interested in seeking out the knowledge, skills, and abilities to make their dreams a reality. This interest in seeking out knowledge relates to the idea of agency which we expand upon in the following paragraph.

Makerspaces are promising venues for supporting agency [15] and endeavors that are personally meaningful to the Maker. Makers experience that they can be agents of change for themselves and their lives, and even for issues affecting others. In-line with the idea of Making being natural to people, we posit that human agency is at the core of Making and is necessary in the individual's pursuit of whatever they make. You can see Maker's agency and what they see as personally meaningful in the diversity of the artifacts they make, as well as the diversity of the reasons people get involved in Making. At First Build, a GE appliances-backed initiative, in Louisville, and the artifacts push the boundaries of electrical appliances technology [16]. While at the LVL1 [17] Hackerspace down the road in Louisville, many Makers' approach Making from an arts and crafts perspective, which is common among many community Makerspaces. Following this theme of agency, the initiation of some Makerspaces, such as the Philippines Communitere [18], the Maker Movie [19], and the Maker Map [20] which is a map of different Maker initiatives all over the world, have been crowd sourced. The agency that the participants of these and many other initiatives exhibit is a testimony to the power of human agency in Making. Realizing personal meaning and being agentive are contributing factors to individuals' intrinsic motivation [21]. Participants in a Makerspace being intrinsically motivated to engage and learn adds to the promise of their educational potential.

1.2. Potential Challenges in Realizing the Educational Potential of Makerspaces. Educators and writers we cite in this section have expressed caution regarding current and impending challenges in realizing the educational potential of Makerspaces. We elaborate on the following challenges: (1) a lack of diversity within the Maker movement; (2) ideological disconnects between the democratic ideals of human agency and change and the capitalistic forces at play in some Makerspaces; and (3) the challenges associated with replicating successful exemplar spaces in different contexts (e.g., locations and cultures).

Issues of diversity and inclusion in Makerspaces resemble issues of diversity and inclusion in the field of engineering where the dominant culture is masculine, technocentric, and white. Chachra [22] in "Why I am not a Maker" wrote about how the Maker culture promotes differentiation between those who claim to Make and those who do not. Further, she comments on the gender disparities prevalent in the Maker communities. Many of the activities that constitute Making have been associated with men, whereas the values of caring that are often associated with women are devalued by the movement. Buechley added to this concern by her presentation at the MIT third annual Fablearn Conference at Stanford University [23]. She noted that the covers of Make magazine depicted narrow and skewed themes. 53\% of the covers depicted electronics, $31 \%$ vehicles, $22 \%$ robots, $8 \%$ rockets, and 5\% music. Thus, promoting and valuing certain types of Making activities that historically ascribe to masculine, technocentric characteristics. To overcome this challenge and avoid reinforcing cultural and gender stereotypes that have led to this already blooming homogenous Maker culture, educators will need to be thoughtful as they seek out and develop educational Maker activities. Pro-Making educators will need to be intentional about not recreating an environment that favors masculinity as has been observed in Technology Education [24] and Shop Class [25].

The democratic ideals of personal meaning and agency, often seen as potential benefits of the Maker movement, have also been challenged. Morozov in his article in The New Yorker [26], which sparked multiple commentaries and critiques, claimed that even though one tends to associate Making with Marxist values of equal division of capital, it rarely plays out this way. He writes that in a capitalistic society, capital is the best way of getting heard. The rosy ideals of democratization via Making are supported by peoples' abilities to procure funds and get attention for themselves and their artifacts counter to traditional Marxist values. Along these same lines, Driscoll [27] comments on Maker media receiving funding from DARPA in 2012 and the strained historical relationship between military funding and the DIY culture in the United States. Driscoll highlights that DIY enthusiasts have held ideological beliefs that support them in conducting research and development activities for the military. These ideological breaches threaten the educational potential of Makerspaces that aim to serve the broader population of students from diverse and, sometimes, economically disadvantaged communities. Ideally, Making should not depend on access to capitalistic resources; however, the reality is that tools, materials, and resources are needed, and as Morozov [26] warns, gaining access may require engaging sources who may have other capitalistic intents. As Makerspaces become more common 
in educational settings, there is a responsibility to ensure that students in a Makerspace are engaging in the pursuit of knowledge and development of self rather than engaging in a focus on economic benefits to the resource providers.

It has also been proposed that Making empowers people to Make what they like, but that can also jeopardize the fabric of invention and development by reinventing things badly [28]. In an interview to Hsu [29], Neil Gershenfeld, the director of MIT's Center for Bits and Atoms told the following:

... what's wrong with DIY is if you do it by yourself, it's easy to do dumb things... If you learn with other people, you can do it better. A place like MIT is organized but it doesn't scale. We want to scale to a few billion people on the

planet and harness the enthusiasm of the Maker movement, but don't want to reinvent dumb things (para. 14).

Thus, there is a distinct challenge to scale those things that work in unique and particular settings to new and different settings with different people who have different motivations and needs. Resources for developing Makerspaces include procedural manuals $[3,4,30]$ that describe the equipment and materials to be procured for a school Makerspace but little to describe the learning objectives they should address or for how to adjust the design for whom they intend to serve. The existing information on educational Makerspaces is insufficient as we have few resources that bridge the division between the educational benefits of Makerspaces that we describe above to classroom design and pedagogies. The potential benefits of educational Makerspaces we mention above have not been captured in resources for educators to support the scale-up of Makerspaces in schools. This leaves a gap between the ideal nature of Makerspaces and those emerging in educational settings. This gap can be narrowed with more research and practice that leads to the development of resources to aid this scaling-up.

Many proponents of the Maker movement [31-33] have responded to the critiques we highlight above. Common across these responses is the need for dialogue and healthy critique. As Reich writes [34], "we want the Maker movement to inspire changes in schools, that change will come through challenging conversations not purchases." Thus, where there exist many potential benefits of Making, there also exist challenges that require attention and action by researchers and educators. There is a need for critical work that addresses these challenges before we make decisions regarding the adoption of these spaces more commonly. The conceptual framework we introduce below serves as a way to frame the various consideration educators can work through as they develop educational Makerspaces for their unique contexts and settings.

\section{Rationale}

The first aim of this paper is to propose a conceptual framework to characterize Makerspaces as educational spaces. Though previous empirical studies in the area of educational Makerspaces [35-42] answer pertinent questions regarding the implementation and assessment in Makerspace environments, no particular work captures the meaning of Making, and more narrowly Making in educational environments. With this work, we synthesize 53 sources representing Makerspaces in informal and formal settings to propose a conceptual framework to make meaning of educational Making.

Jabareen [43] defines a conceptual framework "as a network or a "plane" of linked concepts" (p. 49). Since many sources used to synthesize the framework are not from the research literature, which is in its infancy for this topic, this conceptual framework could be considered nontraditional for its reliance on popular culture and more informal, self-reported data from Makerspace sites, and philosophies of the curators of the phenomenon of Making. However, similar to traditional conceptual frameworks and the methods of their creation, it remains a network of linked concepts generated using a methodology of synthesizing sources in which the phenomenon of Making is grounded. Precedence for the development of such a nontraditional conceptual framework exists. Pintrich [44] developed a conceptual framework for understanding the different types of self-regulated learning based on the assumptions associated with common models of self-regulated learning. Eshet-Alkalai [45] forwarded a conceptual framework to accommodate the multiple ways in which the term "digital literacy" presents itself in the literature. Previously misunderstood as either only technical or cognitive and socioemotional, Eshet-Alkalai [45] synthesized the existing literature and practices to propose a framework that accommodates the multiple dimensions of digital literacy, such as "photo-visual literacy; reproduction literacy; branching literacy; information literacy; and socio-emotional literacy" (p. 93). Lin's [46] framework on creative pedagogy uses a confluence approach to illuminate the relationship between creativity and pedagogical practices and is informed by the ways in which creativity is nurtured in educational settings and the assumptions present behind prevalent theories of creativity. In the field of engineering education, constructing frameworks and presenting syntheses of newer concepts have also been accepted. Several new phenomena have been conceptualized by researchers to propose future directions for research and practice. For example, a synthesis by Brophy et al. [47] to detail the future direction for Engineering Education in P-12 classrooms is a synthesis of classroom models and educational engineering practices existing in the academic literature. Similarly, Feisel and Rosa [48] synthesized the available literature on the history of laboratory education in engineering, assessment, introduction of computers, and hands-off laboratory learning, to propose fundamental objectives for laboratory education for undergraduate engineering students, and also possible future directions for research. Given these examples and the relative lack of the academic literature on the topic of Makerspaces as educational learning environments, we believe there is sufficient justification to embark on the development of such a conceptual framework that can continue to be tested and evaluated as more research is published.

\section{Method}

A considerable portion of the development of Makerspaces has happened outside of the realm of the academic literature. Cognizant of this, we undertook a synthesis of definitions of 
TABLE 1: A breakdown of the definitions of Making forwarded by established initiatives within the framework of people, means, and activities.

\begin{tabular}{|c|c|c|c|}
\hline & People & Means & Activities \\
\hline Makerspace & Community & Access to tools and equipment & Design, prototype, create, and educate \\
\hline Hackerspace & Community-operated/Coop & $\begin{array}{l}\text { Digital technology, electronic art, and } \\
\text { other tech (servers, oscilloscopes, and } \\
\text { other raw material) }\end{array}$ & Share, meet, work, and learn \\
\hline Fab Lab & $\begin{array}{c}\text { Place for (people) to play, create, } \\
\text { learn, mentor, and invent }\end{array}$ & Technical prototyping platform & $\begin{array}{l}\text { Innovation, invention, and stimulus } \\
\text { for local entrepreneurship }\end{array}$ \\
\hline
\end{tabular}

Making forwarded by 3 well-established Maker initiatives (i.e., Makerspace, Hackerspace, and Fab Lab), 18 relevant sites of Making activities across the United States, 17 sites from other countries (namely, China, India, Morocco, and Spain), and 15 Maker initiatives at schools in the United States. All Maker experiences can be educational. The 15 Maker initiatives at school represent formal in-school experiences, and the other sources represent informal experiences. This inquiry into the nature of educational Making yielded the conceptual framework we present in the paper, the framework of people, means, and activities. Our process of synthesizing this framework from all 53 sources is, in part, demonstrated by the synthesis of three definitions of Making by established Maker initiatives. These definitions (below) all address the aspects of who uses the space (people), what is used in the space (means), and what is done in the space (activities). Upon realizing that these common themes of people, means, and activities emerged from our demographically and geographically diverse sources, we ceased further data collection. We can hypothesize the same for other sites of Making and hence use our framework to situate them.

\subsection{Makerspace}

Simply put, Makerspaces are community centers with tools. Makerspaces combine manufacturing equipment, community, and education to enable community members to design, prototype, and create manufactured works that would not be possible to create with the resources available to individuals working alone. These spaces can take the form of loosely organized individuals sharing space and tools, for profit companies, nonprofit corporations, organizations affiliated with or hosted within schools, universities or libraries, and more. All are united in the purpose of providing access to equipment, community, and education, and all are unique in exactly how they are arranged to fit the purposes of the community they serve [49].

\subsection{Hackerspace}

Hackerspaces are community-operated physical places, where people share their interest in tinkering with technology, meet and work on their projects, and learn from each other [50] (para. 1).

A hackerspace is basically a coop work area that happens to be oriented around digital technology. Moreover, these can involve electronic art as well. Particularly lavish hackerspaces may include machining technology, servers, oscilloscopes, and even raw materials for creating electronic devices [51] (para. 1).

\subsection{Fab Lab}

Fab Lab is the educational outreach component of MIT's Center for Bits and Atoms (CBA), an extension of its research into digital fabrication and computation. A Fab Lab is a technical prototyping platform for innovation and invention, providing stimulus for local entrepreneurship. A Fab Lab is also a platform for learning and innovation: a place to play, to create, to learn, to mentor, and to invent [51] (para. 1).

The three common themes when looking at the above definitions from an educational perspective are those of people who use the space, means what are used in the space, and activities what are done in the space.These themes were also present in our remaining 49 sources and began mapping well to corollary themes in education, namely, those of educators and students, technology and resources, and curriculum and assessment. In Table 1, we offer a breakdown of the definition within this framework of people, means, and activities.

Work by Sheridan et al. [41] explored three Makerspaces through a comparative case study where they asked the following questions: "Who participates in these Makerspaces; How and to what ends are tools, materials, and processes used in each Makerspace; and What are the arrangements for learning, teaching, and collaborating in each space? (p. 507)" This work also supports the aspects of our framework-people, means, and activities. The first two aspects of our framework relate well to the first two research questions by Sheridan et al. [41], with emphasis on the people and the means used in the space. However, with many spaces not explicitly partaking in teaching and learning activities, the third aspect of our framework includes all activities that may occur in such spaces, but we will often refer to educational activities. Our analysis of recent academic literature in the field of educational Makerspaces also provided support for the people, means, and activities framework for conceptualizing Makerspaces. We cite this work in the directions for future research in a later section.

\section{The Conceptual Framework}

Figure 1 is a representation of our proposed conceptual framework. As depicted, the three aspects of people, means, and activities are interconnected via purpose. The people in 


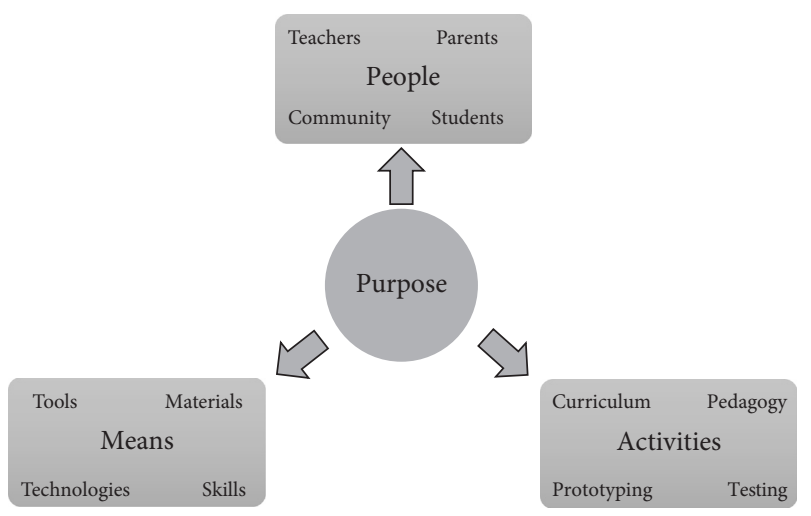

Figure 1: Representation of the proposed people, means, and activities framework for educational Makerspaces.

a Makerspace provide, request for, and dictate the means used, the means determine the activities that may be possible in the space, and the activities contribute to people's experiences which include their learning experiences. At the same time, the people and their interests, goals, and experiences dictate the activities that take place in a Makerspace, the activities determine which means are needed, and the means influence what people do in the space. Depending on the purpose behind the space, each Makerspace could be variably focused toward either the people, the means, the activities of the space, or combination of some of them. We illustrate examples in Figure 2 and explain the role the purpose plays in the following section on purpose. Furthermore in this section, we detail the nature of the people, means, and activities aspects of the framework, and their interconnectedness with examples from our data sources. We also cite examples from Sheridan et al.'s study to show congruency between our and their findings.

4.1. Purpose. As represented in Figure 1, the purpose of a Makerspace defines which aspect(s) the space focuses on. The purpose of a space could be people-focused, meansfocused, or activities-focused, or some variable combination. All aspects of the framework always exist but sit at tension with the variable focus of the space. The purpose of a Makerspace could be defined when the space is initiated, such as Makerspaces in educational settings, which are set up for meeting educational needs or outcomes. The purpose could also be continually evolving as many spaces redefine their nature depending on the contexts they are situated in. Examples of such spaces include community spaces which are not set up for a particular reason but dynamically evolve.

Figure 2(a) represents Makerspaces that are focused toward the people aspect of the framework. The purpose of such spaces is informed by the goals of the individuals or the community of individuals the space serves. Such spaces include those which are set up to serve a community, city, geographical area, or online network. The Maker Library Network, the Makerspace North in Ottawa, and the Maker Camp are examples of some such spaces, which we detail in following section on the people aspect. The means and the activities of such spaces are defined by the people who engage with the spaces.

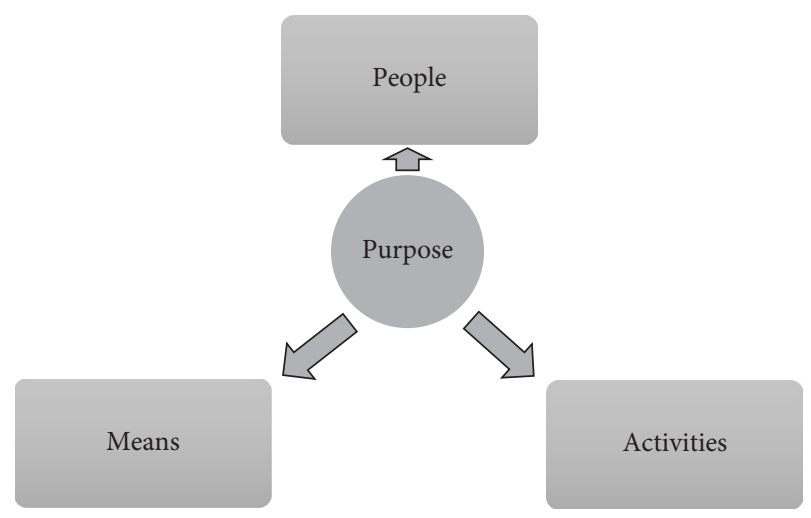

(a)

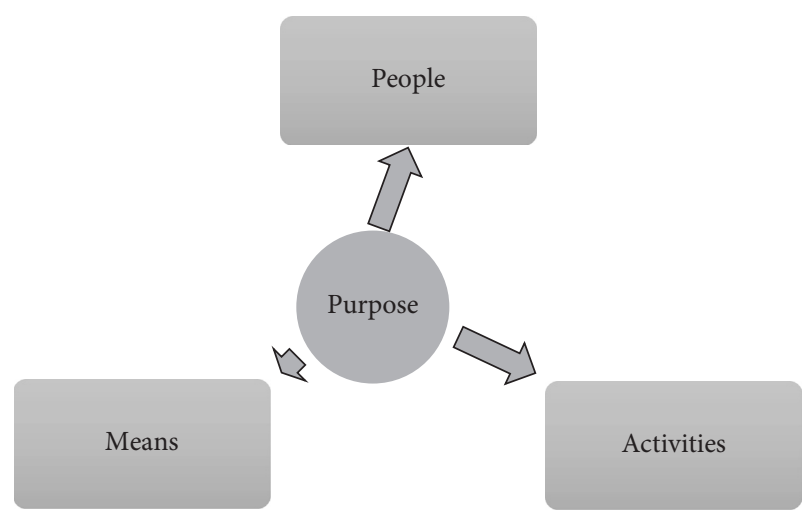

(b)

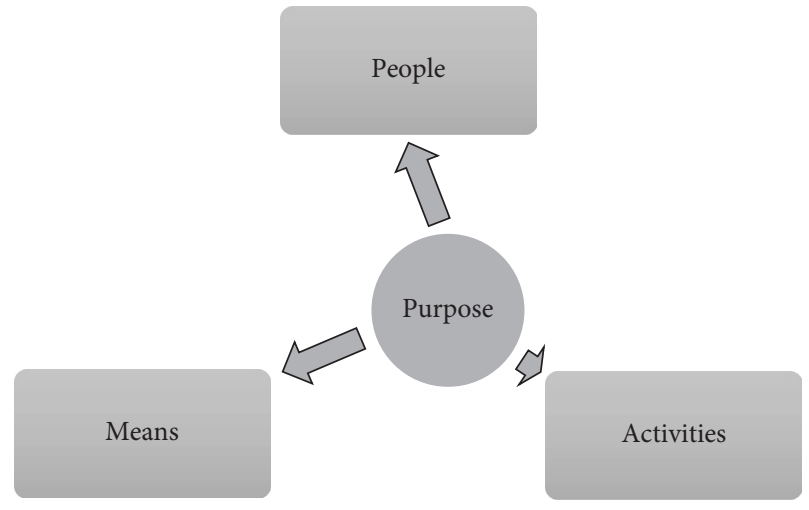

(c)

FIgURE 2: Representation of people-focused (a), means-focused (b), and activities-focused (c) framework.

Figure 2(b) represents Makerspaces focused toward the means aspect. The purpose of such spaces is to house certain tools and technologies that aid Making. Such spaces attract enthusiasts who are drawn to the novelty of rapid prototyping and using innovative tools and technologies. Spaces set up in accordance with manuals from Maker Media, Fab Lab, and other online documents and blogs, which we detail in our discussion on the means aspect, are examples of such spaces. The means attract people interested in using them, and the means inform the activities the people end up engaging with.

Figure 2(c) represents Makerspaces focused toward the activities aspect of the framework. The purpose behind such spaces is to serve as venues for activities of a particular kind. 
Activities could include educational activities, such as those in schools and libraries. Makerspaces at the Steward Middle Magnet School in Tampa, Mountain View Elementary School, and First Build in Louisville are examples of such spaces, which we detail in our discussion on the activities aspect. The people entering the space and the means procured are dependent on the activities being conducted in the space.

The conceptual framework we propose in this paper and particularly the aspect of purpose can be used as a tool by educators and facilitators to be more purposive about the Makerspaces they are initiating or working within. Depending on the context, educational Makerspaces are likely to be focused on the activities aspect. Knowing this focus, we can decide upon the other aspects. For example, a Makerspace in a school should procure means informed by the educational activities they want to undertake, which might not always necessitate the purchase of expensive equipment.

4.2. The People. The people aspect of a Makerspace refers to the individuals who make or participate in such spaces and the community of people thus created. The individuals' experiences and the experiences shared as a whole by a community of Makers all inform this people aspect of our conceptual framework for educational Makerspaces. Sheridan et al. [41] noted the most distinct feature between Makerspaces was the diverse learning arrangements which were defined by the individuals in the space and how they came together. They reported that, at Sector 67, the people in the space are "the most valued aspect of the space" (p. 513). The director of the space reports that there had been a transformational shift as to how they understood the purpose of the space. When they began, they thought of it as a place with tools for people to build things, but they came to understand that the space was about the people participating in the space and the interesting things they did to attract others to come in and engage. At the Mt. Elliott Makerspace, most of the Makers are between eight and nineteen years of age, which dictates the ways the space is managed, the hours of operation, and its philosophy. The only full-time employee is the founder of the space, other adults, and younger interns take on paid roles that require particular skills as required. The space operates the entire day on Sundays, after school, and twice a week in the evenings. The people aspect of the Makeshop in the Children's Museum in Pittsburgh, Pennsylvania, is very different as compared to Area 67 and Mt. Elliott. The Makers at this space are museum-goers mostly ranging from toddlers to teens. These Makers are often accompanied by their families, and of more than 260,000 visitors to the museum, 50,000 are students and families from low-income backgrounds. The space does not have one person at the helm of affairs, rather teaching artists who have experience in Making support the projects and other workshops at the space. Participants come in for a limited amount of time to Make and receive support and facilitation from the teaching artists. Just from Sheridan et al.'s comparative case study, we see variety in how the people shape a Makerspace [41].

Makerspaces are places for people from different backgrounds to come together and share expertise, experiences, and instruments. Some of these communities are purely virtual, such as the Maker Library Network [53] that spans across continents and connects designers and Makers internationally to share ideas and resources. Other communities share a physical space where Makers congregate to gain access to space and equipment for their Making. The community of Makers that come together at Makerspace North in Ottawa [54] hosts regular events, so Makers can showcase their work and to collaborate amongst the members. These communities then share a virtual space over the Internet to organize the development of camps and other events. The Maker Camp [55] is one such initiative for people to find Maker initiatives around them and create new ones. Thus, as is apparent in these descriptions, the people involved are what make the Makerspace possible in the first place.

Similarly, the people in a school Makerspace drive the experiences for themselves and their classmates. At Stewart Middle Magnet School in Tampa, Florida, 10-15 students gather together in their library outside of class sessions to work on projects [14]. They collaborate with students from the Lamar Middle School in Texas over web-based video conferences. At the Summit Elementary in Oconomovac, Wisconsin, students who showed little to no leadership and interest in schoolwork are becoming leaders through their participation in the school Makerspace [56]. The students are becoming more social and developing moral character traits. Before the Makerspace, at the Big Walnut Middle School in Sunbury, Ohio, for some days, only ten or fewer students entered the library. After setting up the Makerspace, the school claims to have increased its library's traffic by 1000 percent [57]. Like most curricular interventions in schools, Maker activities are often designed and implemented by the teachers. The teachers' conception of Making directly impacts the kinds of activities students engage with. For example, at Mountain View Elementary School, the teachers design activities around the engineering design process and to meet National Educational Technology Standards (NETS) objectives [58], at Summit Elementary, the teachers use Making as an opportunity for younger and older students to pair-up, and at Longfellow Middle School, the teachers plan to use Maker activities as an opportunity to lead activities that cater to the diverse interests of their students such as knitting, robotics, web coding, and coloring [59].

4.3. The Means. The means of a Makerspace refers to the tools and materials used within the space to produce artifacts. The means are not limited to expensive technologies such as $3 \mathrm{D}$ printers, which in certain groups have been the face of the Maker revolution [60, 61]. Any tools, methods, or materials used to create artifacts represent the means for creating in a Makerspace.

As a common theme across the three Makerspaces of the comparative inquiry, Sheridan et al. [41] note that "Makerspaces' multidisciplinarity fuels engagement and innovation" (p. 526). In this section, we present the diversity of means across Makerspaces and how they play an important role in defining the space. The means within a Makerspace are defined by the people in the space, and the purpose they have set 
for the environment. With the membership at Sector 67 being mostly adults, the means are defined by the projects and the needs of the Makers. The space is adapted as per the requirements of the community, and the needed equipment is purchased. At Mt. Elliott the founder, Jeff Sturges, aims to develop a model for Makerspaces that can thrive in underresourced neighborhoods by minimizing expenses and ensuring no financial barriers to participation, which leads to certain means being available. Located in the basement of a Church, the space is separated into shops for different purposes such as repairing bikes, woodworking, electronics, and silk-screening. These spaces, however, are converted from what already existed at the church. For example, a storage room full of junk was cleared out to make room for a woodshop. Like Sector 67, Mt. Eliott also responds to the continuously changing needs of its members by acquiring new tools and materials when possible. As compared to Sector 67 and Mt. Elliott, Makeshop follows more structure with the resources it houses. This structure is attributable to it being in a museum with a continuously changing membership leaving little room for acquiring tools and materials corresponding to the users' demands. The Makeshop is strategically divided into three parts- to introduce Making to young children, the Digital Dream Lab to understand object-oriented programming in an interactive manner, and a workshop with tools that require adult supervision.

The means available in Makerspaces vary from space to space and are dependent on the purpose and objectives of the space, such as community engagement, educational attainment, skill building, or entrepreneurship. Where some institutions may find it helpful to procure tools and materials prescribed by Maker Media and Fab Lab in documents such as $[3,4,30]$. Other blogs, manuals, and documents $[5,62,63]$ are less prescriptive with the tools, materials, and internal layouts they suggest. Thus, where some sites abide by established initiatives defining the means of their space, others choose means by other methods. Further within Makerspaces, Makers have different levels of control over procurement depending upon the setup of the space. Though the means across Makerspaces are different, they all utilize tools and materials to Make. Like the people, the means in a Makerspace play a critical role in defining and guiding what is possible in the space.

At the Summit Elementary, the Making resources are stored in a mobile engineering cart. This cart has K'NEX, LEGO, magnet blocks, and tubing connectors and is taken to the students rather than the students coming to it. At Stewart Middle School, students have access to an open Making area where they can use K'NEX, build on their LEGO wall, and sketch on whiteboard walls and tables. They can also use other Making related products such as the LittleBits, MaKey MaKey, Cubelets, and Spheros. The Longfellow Middle School also recently renovated their library with a $\$ 17,200$ grant from the Education Foundation of Wauwatosa for the 2016-17 school year. This renovation involved equipping the library Makerspace with tools and technologies for students to be able to tinker, invent, and solve problems. The means in the school Makerspaces are not just limited to the usual candidates for rapid prototyping such as 3D Printers and Laser cutters, but some schools such as the Mountain View Elementary School have procured means that best suit their teaching and learning. They have laptop workstations, Smartboards, a Hue projector, and student cameras, in addition to a $3 \mathrm{D}$ printer and scanner, building materials, and other tools. Thus, schools adapt the tools and materials that form the means aspect of a Makerspace, according to their needs. Depending upon the prevalent curriculum, extracurricular activities, interests of student, parents, and teachers, the means in the Makerspace are procured and used.

4.4. The Activities. Activities represent all that goes into the Making of an artifact (e.g., planning, research, prototyping, building, and testing). These may be formal, curricular activities that help Makers learn different skills and/or knowledge, or they may be informal activities the Makers engage with to Make their artifacts. All the activities that occur in the space via the interactions between and among the people and the various means constitute what we define as the activities part. In this section, we elaborate on the different kinds of activities that members and nonmembers are privy to in such spaces.

Since different people make differently, the learning and other related activities are as unique as each individual. As is noted by Sheridan et al. [41], the "learning is in and for the making" (p. 528). The Making activities in Sector 67 range from Making for personal use to larger industrial design projects that the members are working on for their startup companies. The members working in this space are trained on the use of the equipment by other more experienced members. The activities at Mt. Elliott cover varied contexts such as "transportation, food, digital tools and electronics, design and fabrication, music, and art" (p. 516). Many of the younger members of this space became regular members after attending structured workshops on Making. Similar to Sector 67, the members are expected to share skills with other members, including the younger members. The activities at Makeshop are defined by the transient nature of the members, and thus, there is no evidence for sharing knowledge among members. The teaching artists who are considered experts support the Making projects within the space.

Similar to the means, the activities across Makerspaces also differ. These activities include, but are not limited to, personal learning, community formation, and corporate innovation. Locally owned Makerspaces such as Artisan's Asylum in Somerville [64] provide a space, amenities, and a community for members. The Fab Lab in the College of Architecture in Seville, Spain, focuses on solving problems faced by other residents of the city [65]. At a space like First Build, Makers work to come up with state-of-the-art solutions using cutting-edge technology supported by GE Appliances [66]. The activities aspect of Makerspaces is deeply connected to the people and the means aspects. The activities that Makers partake in are dependent on the individuals who Make or participate in such spaces, the community of people thus created, and also the tools and materials used within the space to produce artifacts.

In schools such as Summit Elementary, Making activities are a part of the schoolwork and the teachers design STEM 
activities to take place in their Makerspace. They also organize STEM challenges and buddy classes that pair up younger and older students. Similarly, at Stewart Middle Magnet School their pop-up Maker stations often are connected to the curriculum. They also scaffold the Making by leaving appropriate design prompts next to materials. An instance of connecting Making to their curriculum is a "Design a Rocket" station for the annual Space Week celebration. In the first year of their new library Makerspace at the Longfellow Middle School, the school planned to cater to diverse student interests. They planned to introduce projects such as knitting or crocheting, robotics, web coding, and coloring books. At Agnor Hurt Elementary School in the Albemarle County in Virginia, students from different grades Make together [67]. They encourage students to choose their projects as they believe that to be the best way to Make. At the Mountain View Elementary School, the lessons in the Makerspace are related to the engineering design process and NETS learning objectives. Thus, the activities that students in school Makerspaces partake in are contingent upon the affordances allowed by the existing curriculum and resources spent on extracurricular activities.

\section{Directions for Future Research}

The conceptual framework we propose in this paper along with theories of learning and development that align with the three aspects of the framework can provide a foundation for determining best practices for learning and development in a Makerspace. These best practices will have important implications for developing educational programming at Makerspaces in schools, colleges, museums, libraries, and other educational settings.

We believe that the people, means, and activities framework can also help articulate directions for future research. The concerns of Vossoughi et al. [68] and Chachra [22] regarding Making not being equitable relate to the people aspect of the framework. There is a need for research on how different people want or do not want to engage in educational Makerspaces. Further, issues of broadening participation and social justice arise as we consider who has access to such spaces in their schools and communities. In addition to researching questions pertaining to equitable access to Makerspaces, research is needed to understand how Making affects people from different age groups, whether it is better suited for informal environments than formal environments like schools, and what their meaningful implementation in educational settings looks like. With our work and recommendations, we initiate this conversation of meaningful Making.

Another series of questions to be addressed to make Making more equitable and accessible are related to the technological means used in the space. Using new and innovative technologies is one of the primary reasons many Makers make. The educational potential of Makerspaces explained by constructionism also relies heavily on the use of technology. Meehan et al. [39] report that while working on a card-sorting task in a Makerspace environment, their participants' focus moved from the task they were working on to the technology they were using. The means aspect of
Makerspaces is heavily understudied and needs to reach beyond the prescriptive pieces on means to procure to set up a Makerspace. Fundamental questions such as what educational affordances do different means provide, how may some means limit learning, and what means are most affective for school/classroom use, need to be answered.

The activities aspect is the most-studied aspect of Makerspaces so far. The literature has helped shed light on opportunities for Makerspaces at libraries [35], potential learning opportunities [40,42], diverse exemplar sites for Making [41], and examples of tinkering at such spaces [36]. However still, the activities aspect of educational Makerspaces will benefit from clearly defined curriculum, best practices, and an understanding of the efficacy of different educational activities with respect to different learners. Adding to this, we believe that the community will benefit from large-scale work that captures the Maker movement in different cultures, understands and captures lessons to learn from various sites, and seeks to understand psychological and sociological phenomena behind the success of Making that we might be missing in our present conversations. The people, means, and activities framework that we propose can form the basis of such conversation and a virtual repository of structured information from Makerspaces all over the world. Such information can merit further analysis to answer the pertinent questions we raise in this section, and other questions from pro-Making educators and researchers.

\section{Conclusion}

Situated in the growing numbers of new Makerspaces, articles in popular media, curriculum, and empirical studies, this work conceptualizes how Makerspaces have evolved and are being adapted to educational settings. We propose a conceptual framework comprising three aspects, namely, the people, the means, and the activities. The three aspects are tied together by the purpose of the space, which can be variably focused toward either of the three aspects.

This framework can be used as a tool by educators and facilitators to be more purposive about the Makerspaces they are initiating or working at. The framework is synthesized from a breadth of sources that include definitions forwarded by established Maker initiatives, relevant sites of Making activities in the United States, sites of Making from four other countries, and Maker initiatives at schools in the United States. We culminate our discussions by suggesting directions for future research that pose meaningful questions to realize the educational potential of Makerspaces and also take into consideration the challenges associated with the phenomenon.

Our proposed framework is a much-needed contribution to the gap in knowledge that exists in current Maker education literature. Work in this paper conceptualizes Makerspaces and provides considerations to realize their purported educational potential. The terms used in the framework are flexible, and the framework can be modified as the phenomenon of Makerspaces evolves and helps understand the phenomenon rather than predicting it. All three of these characteristics, flexibility, capacity for modification, 
and understanding are advantages of a good conceptual framework [43]. All three aspects of the framework, people, means, and activities, are amenable, which will prove beneficial to develop the phenomenon further. An example of this amenability is the recommendation and future research path we highlight in this work. Also, one of the biggest challenges that educational Makerspaces face in the present day is to attain equitable access for all people rather than a few communities that the movement has favored. Our framework to a great extent isolates Makerspaces from the qualities that lead to only a few engaging with them. We do not suggest who is Making, what is being Made, what is being used to Make, or where the Making is happening.

\section{Disclosure}

The views and conclusions contained in this paper are those of the authors and should not be interpreted as necessarily representing the National Science Foundation.

\section{Conflicts of Interest}

The authors declare that there are no conflicts of interest regarding the publication of this paper.

\section{Acknowledgments}

This work was supported by the National Science Foundation (CAREER-EEC-1454152).

\section{References}

[1] K. Bannan, Makerspaces Encourage Students to Innovate and Build Critical Thinking Skills, December 2017, https://edtechmagazine. com/k12/article/2016/10/makerspaces-encourage-studentsinnovate-and-build-critical-thinking-skills.

[2] K. Peppler and S. Bender, "Maker movement spreads innovation one project at a time," Phi Delta Kappan, vol. 95, no. 3, pp. 22-27, 2013.

[3] Maker Media, High School Makerspace Tools and Materials, April 2012, http://spaces.makerspace.com/wp-content/uploads/ 2012/04/hsmakerspacetoolsmaterials-201204.pdf.

[4] Maker Media, Makerspace Playbook School Edition, 2013, http://makered.org/wp-content/uploads/2014/09/MakerspacePlaybook-Feb-2013.pdf.

[5] E. McManus, Start Your Own FabLab: \$1,499, 2009, http:// blog.ted.com/start_your_own/.

[6] K. Peppler, A. Maltese, A. Keune, S. Chang, and L. Regalla, The Maker Ed Open Portfolio Project: Survey of Makerspaces, Part II. Open Portfolios, 2015.

[7] D. L. Rendina, Makerspace Resources, August 2016, http:// renovatedlearning.com/makerspace-resources/.

[8] D. Dougherty, "The maker movement, Innovations: Technology, Governance, Globalization," vol. 7, no. 3, pp. 11-14, 2012.

[9] M. Hatch, The Maker Manifesto, 2014, http://www.techshop. ws/images/0071821139 Maker Movement Manifesto Sample Chapter.pdf.

[10] A. Dubrow, Democratizing the Maker Movement, December 2017, https://www.huffingtonpost.com/aaron-dubrow/democratizingthe-maker-m_b_7960540.html.

[11] Make It Lab, August 2016, http://www.makeitlabs.com/space-1/.
[12] S. Durham, Makerspaces Making Future Dreams a Reality, 2015, http://lufkindailynews.com/news/community/article_ c97bf88c-5b66-11e5-a0c4-e379a502c6b2.html.

[13] S. Barniskis, "Steam: science and art meet in rural library makerspaces," in iConference 2014 Proceedings, IL, USA, 2014.

[14] D. Rendina, Makerspaces in Schools: Creating STEAM Connections, December 2017, http://ideas.demco.com/blog/makerspaces-inschools/.

[15] A. Keune, A. Gomoll, and K. Peppler, Flexibility to Learn: Material Artifacts in Makerspaces, December 2015, http:// creativitylabs.com/pubs/2015_Keune-Gomoll-Peppler_FlexLearnMatArtifacts_FabLearn.pdf.

[16] M. Wollerton, GE's FirstBuild Facility Opens Its Doors, December 2017, https://www.cnet.com/news/ges-first-buildfacility-opens-its-doors/.

[17] LVL1, LVL1 Louisville Hackerspace, December 2017, http:// www.lvl1.org/.

[18] T. Bulthuis, Communitere: Make It Happen in the Philippines, 2014.

[19] Maker, A documentary on the Maker Movement, June 2015, https://www.kickstarter.com/projects/379201360/maker-adocumentary-on-the-maker-movement/comments.

[20] Hwstartup, The Maker Map, December 2017, http:// themakermap.com/.

[21] E. Deci and R. Ryan, Intrinsic Motivation and SelfDetermination in Human Behavior, Springer, New York, NY, USA, 1985.

[22] D. Chachra, Why I Am Not a Maker, The Atlantic, 2015, https://www.theatlantic.com/technology/archive/2015/01/whyi-am-not-a-maker/384767.

[23] C. Quattrocchi, MAKE'ing More Diverse Makers, 2013, https://www.edsurge.com/news/2013-10-29-make-ing-morediverse-makers.

[24] E. Bame, W. Dugger Jr., M. de Vries, and J. McBee, "Pupils" attitudes toward technology-PATT-USA," Journal of Technology Studies, vol. 19, no. 1, pp. 40-48, 1993.

[25] D. L. Collinson, “"Engineering humour”: masculinity, joking and conflict in shop-floor relations," Organization Studies, vol. 9, no. 2, pp. 181-199, 1988.

[26] E. Morozov, Making It, The New Yorker, 2014, https://www. newyorker.com/magazine/2014/01/13/making-it-2.

[27] K. Driscoll, The Dark Side of DIY-Makersapces and the Long, Weird History of DIY Hobbyists and Military Funding, September 2016, http://civicpaths.uscannenberg.org/the-dark-side-of-diymakerspaces-and-the-long-weird-history-of-diy-hobbyistsmilitary-funding/.

[28] A. R. Galloway and G. Hertz, Critique and Making, 2015, http://ctheory.net/articles.aspx?id=757.

[29] J. Hsu, Why a DIY Pioneer Dislikes 3D Printing, September 2016, http://www.livescience.com/20762-diy-pioneer-3dprinting.html.

[30] Fab Foundation. (n.d.-a), Setting Up a Fab Lab, http://www. fabfoundation.org/fab-labs/setting-up-a-fab-lab/.

[31] K. Costanza, The Maker Movement Gets a Dose of Critique, September 2016, http://remakelearning.org/blog/2015/02/23/ the-maker-movement-gets-a-dose-of-critique/.

[32] B. Doherty, Why Be a Maker When You Can Be a Re-Maker? (of Society According to Your Ideological Predilections), December 2017, http://reason.com/blog/2014/01/23/why-bea-maker-when-you-can-be-a-re-make.

[33] N. Mirra, Is the Maker Movement Equitable, September 2016, http://dmlcentral.net/is-the-maker-movement-equitable/. 
[34] J. Reich, The Lure of the Technological Sublime: Morozov and the Makers, 2014, http://blogs.edweek.org/edweek/ edtechresearcher/2014/01/the_lure_of_the_technological_ sublime_morosov_and_the_makers.html.

[35] S. Abram, "Makerspaces in libraries, education, and beyond," Internet@Schools, vol. 20, no. 2, pp. 18-20, 2013.

[36] B. Bevan, J. P. Gutwill, M. Petrich, and K. Wilkinson, "Learning through STEM-rich tinkering: findings from a jointly negotiated research project taken up in practice," Science Education, vol. 99, no. 1, pp. 98-120, 2015.

[37] B. Gravel, E. Tucker-Raymond, K. Kohberger, and K. Browne, "Navigating worlds of information: STEM literacy practices of experienced makers," International Journal of Technology and Design Education, pp. 1-18, 2017.

[38] M. Hynes and W. Hynes, "If you build it, will they come? Student preferences for Makerspace environments in higher education," International Journal of Technology and Design Education, pp. 1-17, 2017.

[39] R. Meehan, B. Gravel, and B. Shapiro, Card-Sorting Task to Establish Community Values in Designing Makerspaces, October 2015, http://fablearn.stanford.edu/2014/wpcontent/ uploads/fl2014_submission_55.pdf.

[40] R. Morocz, B. D. Levy, C. R. Forest et al., "University maker spaces: discovery, optimization and measurement of impacts," in Proceedings of the 122nd ASEE Annual Conferenece \& Exposition, Seattle, WA, USA, June 2015.

[41] K. Sheridan, E. R. Halverson, B. Litts, L. Brahms, L. JacobsPriebe, and T. Owens, "Learning in the making: a comparative case study of three makerspaces," Harvard Educational Review, vol. 84, no. 4, pp. 505-531, 2014.

[42] P. S. Wardrip and L. Brahms, "Learning practices of making," in Proceedings of the 14th International Conference on Interaction Design and Children (IDC'15), pp. 375-378, New York, NY, USA, June 2015.

[43] Y. Jabareen, "Building a conceptual framework: philosophy, definitions, and procedure," International Journal of Qualitative Methods, vol. 8, no. 4, pp. 49-62, 2009.

[44] P. Pintrich, "A conceptual framework for assessing motivation and self-regulated learning in college students," Educational Psychology Review, vol. 16, pp. 385-407, 2004.

[45] Y. Eshet-Alkalai, "Digital literacy: a conceptual framework for survival skills in the digital era," Journal of Educational Multimedia and Hypermedia, vol. 13, no. 1, pp. 93-106, 2004.

[46] Y.-S. Lin, "fostering creativity through education-a conceptual framework of creative pedagogy," Creative Education, vol. 2, no. 3, pp. 149-155, 2011.

[47] S. Brophy, S. Klein, M. Portsmore, and C. Rogers, "Advancing engineering education in P-12 classrooms," Journal of Engineering Education, vol. 97, no. 3, pp. 369-387, 2008.

[48] L. D. Feisel and A. J. Rosa, "The role of the laboratory in undergraduate engineering education," Journal of Engineering Education, vol. 94, no. 1, pp. 121-130, 2005.

[49] Make. (n.d.), What's a Makerspace, September 2016, http:// spaces.makerspace.com/.

[50] Hackerspaces.org. (n.d.), Hackerspaces, December 2017, http://hackerspaces.org/.

[51] D. Vega, What's a Hackerspace, 2013, http://heavy.com/social/ 2013/08/hackerspace-meaning-mean-definition-define/.

[52] Fab Foundation. (n.d.-b), What is a Fab Lab, September 2016, http://fabfoundation.org/what-is-a-fab-lab/.

[53] The British Council. (n.d.), Maker Library Network, January 2015, http://makerlibrarynetwork.org/.

[54] Makerspace North, Makerspace North, December 2015, http:// makerspacenorth.com/.
[55] Make, Maker Camp, December 2015, http://makercamp. $\mathrm{com} /$.

[56] E. Ullman, Making the Grade: How Schools are Creating and Using Makerspaces, December 2017, http://www.techlearning. com/resources/0003/making-the-grade-how-schools-are-creatingand-using-makerspaces/69967.

[57] J. Gonzalez, How This School Library Increased Student Use by 1,000 Percent, December 2017, https://www.cultofpedagogy. com/school-library/.

[58] Mountain View Elementary School, Welcome to the Digital Hub!, December 2017, https://mountainviewes.pwcs.edu/ our_school/makerspaces.

[59] R. Minske, Tosa School Libraries Gear Up for Fall Introduction of "Makerspaces", December 2017, http://archive.wauwatosanow. com/news/tosa-school-libraries-gear-up-for-fall-introduction-ofmakerspaces-b99731582z1-380744671.html/.

[60] E. Parker, In China, Lessons of a "Hackerspace", December 2015, http://www.wsj.com/articles/SB100014240527023037 22604579111253495145952.

[61] S. Phillips, Interview with Heramb Maker Lab: 3D Printing Makerspace in India Attracts People of All Ages, December 2015, http://www.inside3dp.com/interview-heramb-makerlab3d-printing-makerspace-india-attracts-people-ages/.

[62] M. Gunby, High Tech Makerspaces, 2015, http:// publiclibrariesonline.org/2015/01/high-tech-makerspaces/.

[63] W. Hynes, M. Hynes, and A. Hira, "Applying the makerspace model to the K-12 classroom," Educational Facility Planner, vol. 49, no. 1, pp. 35-38, 2015.

[64] Artisan's Asylum, About Us, December 2016, https:// artisansasylum.com/about/.

[65] Escuela Tecnica Superior de Arquitectura, About Fablab, December 2016, http://fablabsevilla.us.es/index.php/que-es.

[66] 1B First Build, Who We Are, December 2016, https:// firstbuild.com/about/.

[67] M. J. Madda, Albemarle County Schools' Journey from a Makerspace to a Maker District, December 2017, https://www. edsurge.com/news/2016-05-02-albemarle-county-schoolsjourney-from-a-makerspace-to-a-maker-district.

[68] S. Vossoughi, P. K. Hooper, and M. Escudé, "Making through the lens of culture and power: toward transformative visions for educational equity," Harvard Educational Review, vol. 86, no. 2, pp. 206-232, 2016. 


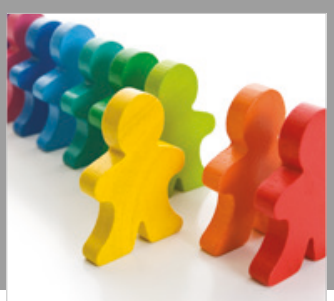

Autism

Research and Treatment
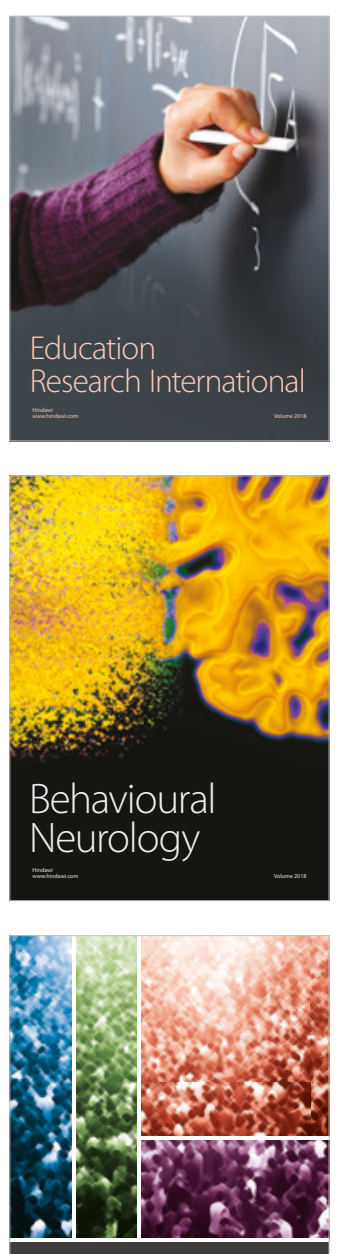

International Journal of

Population Research

$\underline{-m}$

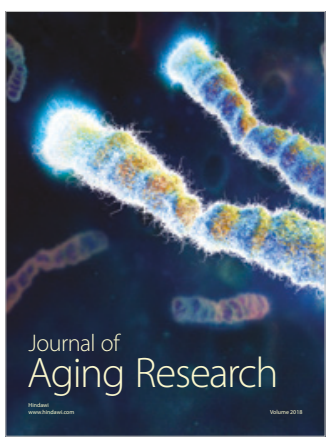

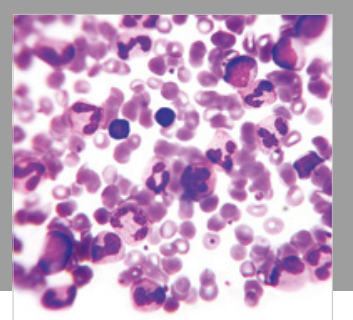

Pathology

Research International$$
=
$$

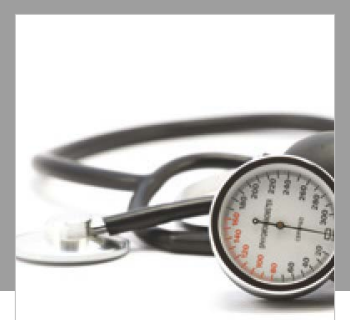

Nursing

Research and Practice

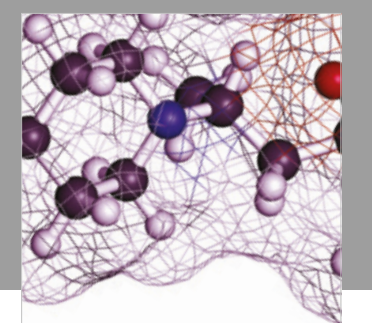

Pain

Research and Management

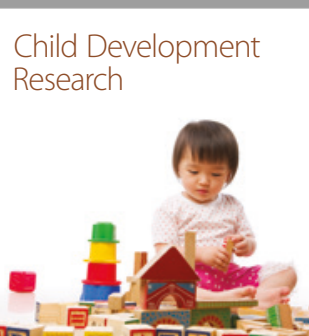

बाD

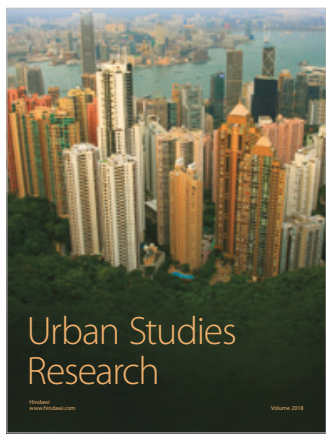

\section{Hindawi}

Submit your manuscripts at

www.hindawi.com
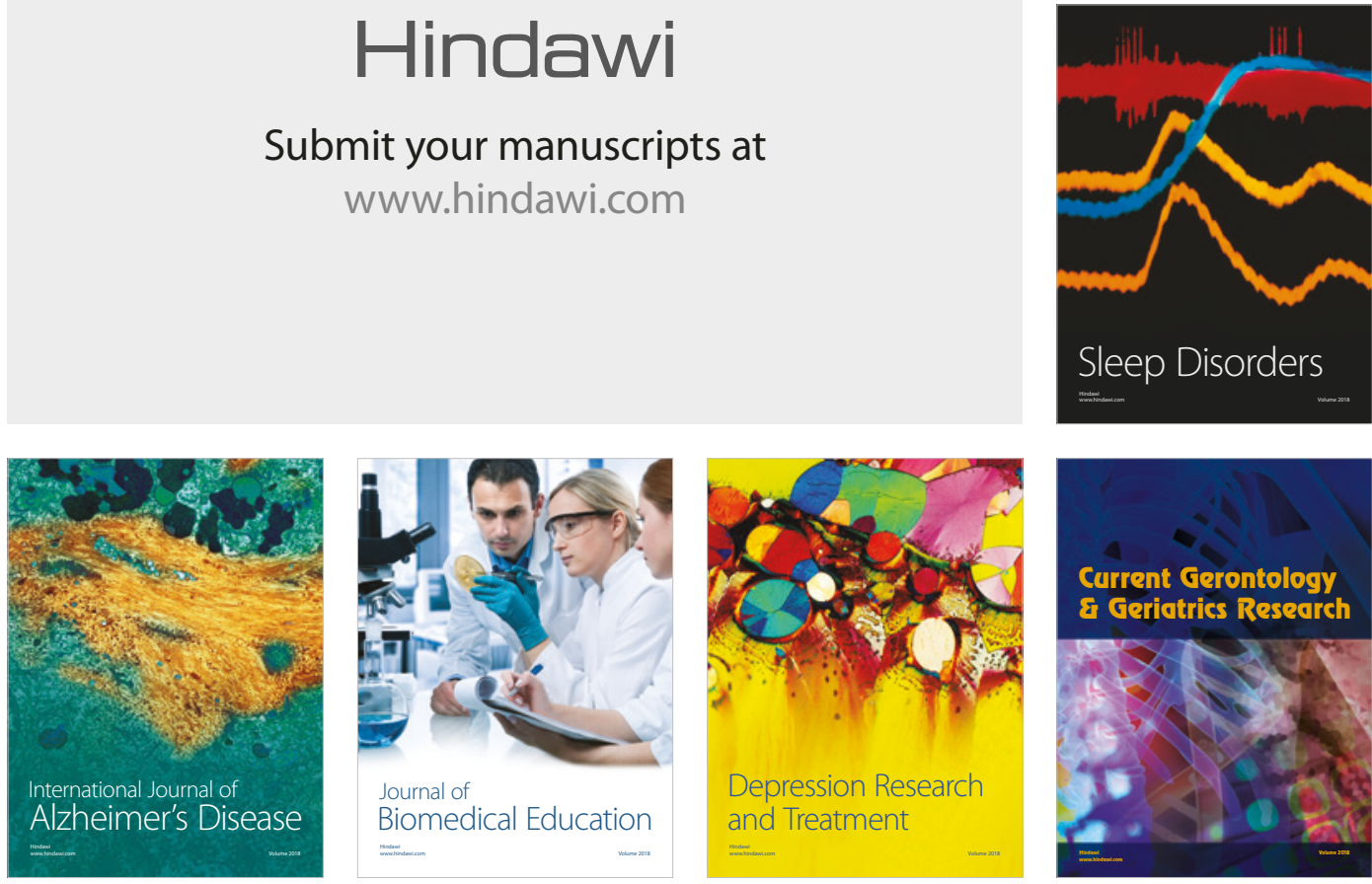

Journal of

Biomedical Education

$=$

smman

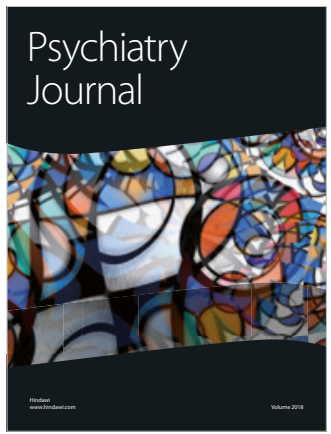

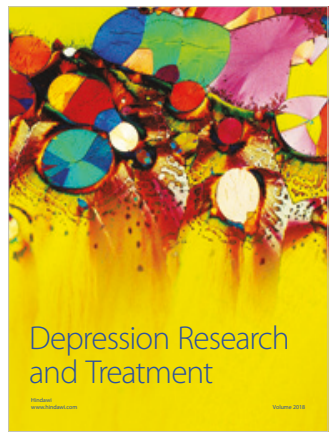
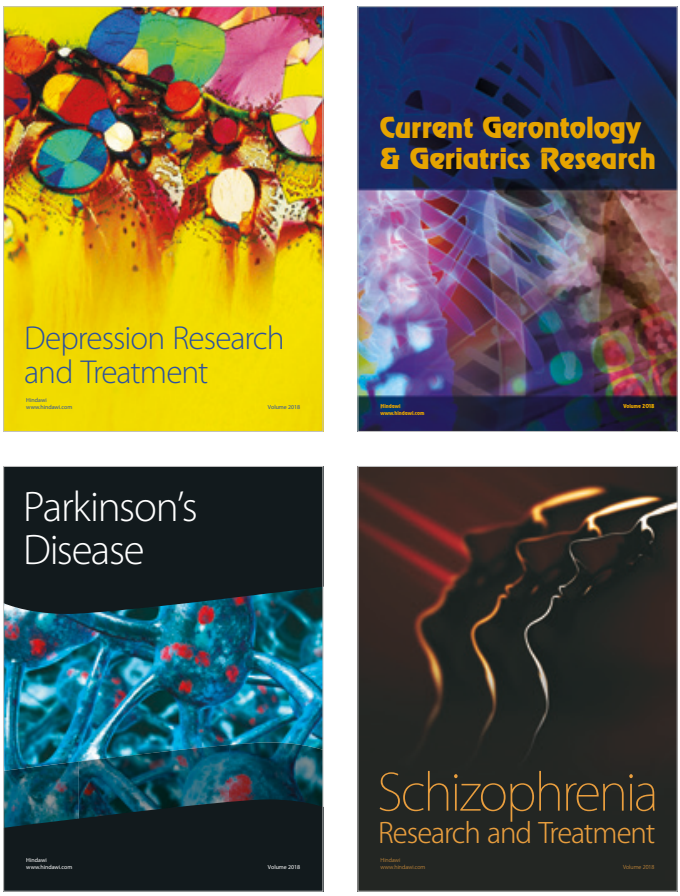